$\S=-1$

\title{
On-line examination system of security application
}

\author{
Tarun Paleti $^{1}$ *, K. Kiran Kumar ${ }^{2}$, Shaik Riyaz ${ }^{1}$ \\ ${ }^{1}$ B. Tech, Department of ECSE, Koneru Lakshmaiah Education Foundation, Vaddeswaram, Guntur, Andhra Pradesh, India 522502 \\ ${ }^{2}$ Professor, Department of ECSE, Koneru Lakshmaiah Education Foundation, Vaddeswaram, Guntur, Andhra Pradesh, India 522502 \\ *Corresponding author E-mail: kiran5434@kluniversity.in
}

\begin{abstract}
Online Examination Framework is Associate in Nursing programming arrangement, That which allows any Education system or institution to orchestrate, direct and superintend exams by suggests that of an internet domain. It may be done through the Web/Intranet and/Neighborhood System things. a little of the problems confronted amid manual examination frameworks ar the postponements occured in result handling, documenting represents a difficulty, separating of records is difficult . the chance of loss of records is high in addition record seeking is difficult . repairs of the framework is in addition exceptionally difficult and takes parcel of your time and labour. on-line examination is one in all the vital elements for on-line instruction framework. it's effective, sufficiently fast and reduces the intensive live of fabric plus. Associate in Nursing examination framework is formed in light-weight of the net. This paper depicts the quality of the framework, displays the basic parts of the framework, breaks down the auto-producing check paper calculation, and talks concerning the protection of the framework.
\end{abstract}

Keywords: Use about five key words or phrases in alphabetical order, Separated by Semicolon.

\section{Introduction}

This paper will tells the highlights of security application of the Online Examination framework. Now a days so many education instruction and organisations are looking toward the conducting of online examinations. There are so many advantages conducting examination on online it can be easy to the students and also the persons who are conducting the exams Including the advantages there are some drawbacks are also there. The main drawback of these online examination system is Security Problems So in this paper we are discussing the security applications

The main use of "On-line Examination System" for any Educational Institute can be use it to prepare their methodology for conducting the exams, and for improving outcomes in less time.

\section{Motivation of the project}

In standard structure coordinating exam is greatly tedious work for expert and instructor as well. The whole technique of allotting examination and evaluating their score once ever the check was completed on it date solely. This kind examination structure is totally electronic structure. The structure is trying for decreasing costs associated with coordinating exams over a time period and achieving complete computerization of examination structure related assignments like enrollment, conveyance of results, which prompts an abnormal state of system viability. In the wake of encountering immense quantities of reference papers at long last we are inferred that we can produced one examination structure that can be offer simple to comprehend access to build up for coordinating exam and examination of result.

\section{Difficulties in present online exam system}

Real downside of online examinations is that a hopeful can without much of a stretch utilization of any unapproved techniques and can appreciate external direction to score great in the examination The related to square measure the thought techniques that fall during this classification:

- Using notes for coordinate direction.

- Using direct direction from a person close-by.

- Utilizing electronic media, place away in Computers Hard Drive, are that accessible on the web

a) Security Application

The fundamental target of this online exam framework is to lessen crafted by leading the exam.

The on-line examinations framework is an electronic application worth valuable everywhere throughout the instructive and private area.

This on-line examinations framework incorporates the compositional segments as Program Server plan, Client-Server Architecture, Auto Question Generator System, Security, Randomization. The Random Number Generator Algorithm is utilized for this framework. It is portrayed forward.

b) Irregular Question Generators

The present programmed paper age frameworks speak to 3 assortments, to be specific: (1) irregular calculation based frameworks, (2) the backtracking framework, and (3) software engineering and information process frameworks. Be that as it may, the essential 2 frameworks can't fulfill the necessities and square measure unfit to enter the sensible stage. The mechanized paper age framework bolstered software engineering and insightful informatics has been enhanced to keep away from the detriments of the 2 calculations said higher than. What's more, on prime of that, the framework is equipped for dealing with inquiries on the intro- 
duce of ability and information. Such a framework regularly builds up a psychological protest and thinking instrument to guarantee a high possibility of accomplishment and nature of examination papers. Be that as it may, the flexibility and upkeep of the examination papers made got the chance to be progressed

All in all, clients could have necessities as respects nature of examination papers, and in addition the amount of subjects, normal level of issue, extent of each type of question, extent of each segment and a couple of key areas and information focuses.

On the premise of computer science and data process, the formula avoids redundancy. within the take a look at, the formula works quickly and selects non-repeated queries every which way. The queries and answers will be with success separated.

c) Finger Impression Recognizable:

Unique finger impression recognizable proof is the most seasoned technique that has been effectively utilized as a part of different applications. Each of our ten fingerprints is not the same as each other and from those of each other individual. Indeed, even indistinguishable twins have one of a kind fingerprints. That makes them perfect for individual distinguishing proof. A unique mark is made of a movement of edges and wrinkles on the surface of the finger. The uniqueness of a special stamp is directed by the case of edges and wrinkles and moreover the subtle elements centers. Subtle elements centers are neighborhood edge qualities that happen when an edge parts isolated or an edge closes.

d) Equipment Design

A unique mark scanner,LCD show, Zigbee appliance what is a lot of, a laptop are going to be used as instrumentality during this venture. wherever the distinctive mark scanner.These mark scanner check a finger impression and sent the candidate figure impression information that which is present in the image to the Zigbee appliance through a Universal Serial Bus association whereas the Individual PC homes the information and runs some necessary application to seem at and coordinative the information finger Impression to be checked distinctive mark. digital display show can show actual all information delicate components knowledge regarding the necessary individual with the help of a association with the laptop.Within the wake of coordinative the information is invigorated naturally. This paper action is completed in 2 methods incoming method and Confirmation method. In incoming methodtells that each person has to place finger on the scanner and each understudy image likewise are going to be caught utilizing internet cam, all the fingerprints and photos are going to store in the database by utilizing zigbee convention, wherever all the finger impressions and photos ar place away aboard their points of interest like: Name, Enrollment id, etc.Second mode is confirmation, during this mode once understudy coming into the examination passageway this framework raise the understudy to place the finger impression on the scanner module and what is more internet catches the image and it send these figure impression to data base. If the figure impressions are same that which are present in the data base then the stepper engine can pivot hostile to clock shrewd heading then entry are going to be open once some deferral, the stepper engine can flip clockastute course then entry are going to be shut through ULN2003, if any finger impression confounds then the signal can blows.

e) Programming Engineering

This online examination Framework is Programming building as Database and Application Program.

Database: The database involves tables that stores records that means the admin who is going to conduct the examination has to upload the details of the students and also the questions that which are required to conduct the exam has upload to database. It can store the information of the students and the details like their Finger Impression and also the results of the students all the information that which are related to the exam are stored in the Database. It can store the data in the form of tables by using the queries we can extract the data that what we want.

f) Attendance of the examinations

\begin{tabular}{lllll}
\hline $\begin{array}{l}\text { No. of } \\
\text { Person }\end{array}$ & $\begin{array}{l}\text { Successful } \\
\text { Identification }\end{array}$ & $\begin{array}{l}\text { UnsuccessfulI } \\
\text { Identification }\end{array}$ & $\begin{array}{l}\text { Present } \\
\text { Percentage }\end{array}$ & $\begin{array}{l}\text { Absent } \\
\text { percentage }\end{array}$ \\
\hline 10 & 9 & 1 & $90 \%$ & $10 \%$ \\
\hline
\end{tabular}

\section{g) Wireless IP Cam}

Our planned technique, "remote information science Cam supported the net examination security" is essentially a video reconnaissance mission arrangement. A connection of video and laptop organizing innovation within the security systems. Lately, owing to increasing security considerations, reconnaissance mission and movement recognition of any articles have clad to be basic Second era arrangements ar altogether laptop construct and might promptly underwrite with regard to existing information science framework as opposition requiring devoted video cabling. information science cameras with freelance video server machines within turn out MPEG, MJPEG,These photos ar created availableto completely different gadgets on the system through a regular information science prepare interface.Monitoring and recording may be performed by altogether programming based mostly system video recorders (NVRs) running on commonplace laptop instrumentation. Progressed video examination programming may be used to naturally acknowledge suspicious occasions or conduct while not having to systematically screen handfuls or many screens. during this paper, Associate in Nursing information science camera based mostly security framework is given wherever there'll be one information science camera for each single understudy occurrence for the examination. As we tend to ar concentrating on the worldwide vendor confirmation examination security particularly, there'll be a limit of range of occurrence understudy in at some point. consistent with our proposition the amount of hopefuls ought not be surpassed over 100. it's planned here that within the room PCs, there'll be a typical internet interface through wherever the action of all the occurrence hopefuls are appeared in a very live approach through information science cameras which is able to be introduced within the examination focuses. during this model, initial the proctor can allot a selected screen (PC) from wherever the challenger can take examination. At that time a reference preview of the challenger is taken by the information science camera and therefore the casing is transferred to the room as appeared. In focal room, the administrator can completely presents a combination and usage of transmittal video and sound data from numerous internet Convention (IP) observation cameras in a very system to a unified administration unit (focal hub) utilizing current Gushing Convention (RTSP). The system depends on "Star" topology by utilizing the IEEE 802.1Q arrangement of tips in Neighborhood Systems (LAN). Security for correspondences between the examination focuses and focal hub (control room) is accomplished ceaselessly through the planned vulnerability order of system movement with very little moreover, unimportant run-time overhead for undesirable movement detection.check the reference depiction of the human whether or not the challenger is maintaining all of the tenets and controls or not. On the off likelihood that everything is common then the hopeful is approved to require the examination else he are ousted comfy that minute. This at first approved casing need to be thought-about as Associate in Nursing 'Intraframe (I)'. This casing is employed for movement identification and undesirable question location. Presumptuous many changes is happened in I define then 'Bi-directional casing (B)' or 'Anticipated casing $(\mathrm{P})$ ' is made. 


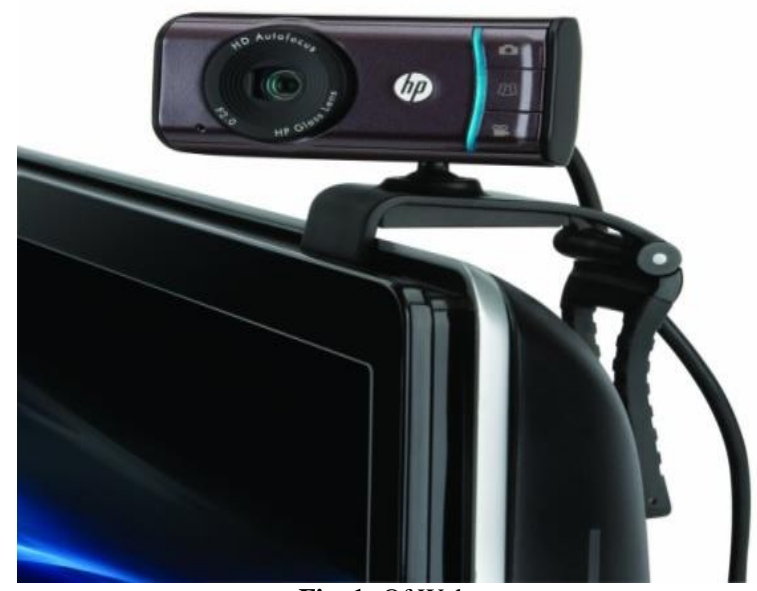

Fig. 1: Of Webcam.

\section{Conclusion}

This paper is executed effectively with essential Prerequisites required for security of on-line examination. The proposed approach utilizes the procedure which consolidates aexceptional biometrics and the idea of remote correspondence. Unique mark gives an answer for ensuring the protection of the client; since the client's actual biometric include is never changed in the entire life. Unique finger impression is utilized to improve things security and exactness. This normal remote security framework can be reached out in future by utilizing a few distinct sorts of required database that will be difficult to break by the aggressors and subsequently it can give better security remote IP Cam based on the web Remote IP Cam based on the web exam security is intended for worldwide accreditation examination By these web cam technique we can increase the security levels of conducting of online examinations.

\section{References}

[1] Echoboomer:www.worldwidewords.org/turnsofphrase/tpech1.htm.

[2] J.-S. Hu and T.-M. Su, "Robust Environmental Change Detection Using PTZ Camera via Spatial-Temporal Probabilistic Modeling”, IEEE/ASME Transactions on Mechatronics, Vol.12, Issue 3, pp. 339-344 (2007). https://doi.org/10.1109/TMECH.2007.897280.

[3] Singh Jat, Chih-HengKe, Poonam Dhaka," Online monitoring system in development of rural area", 3rd International conference on sensing technology, 2008.

[4] ONLINE EXAMINATION SYSTEM DeepankarVishwas Kotwal1, ShubhamRajendra Bhadke2, Aishwarya Sanjay Gunjal3, Puspendu Biswas4

[5] International Journal of Emerging Technology and Advanced Engineering, Website: www.ijetae.com ( ISSN 2250 - 2459, ISO 9001:2008 Certified Journal, Volume 4, Issue 3, March 2014 ) 660 Online Descriptive Examination and Assessment System BhagyashriKaiche 1, SamikshaKalan 2, Sneha More 3 , LekhaShelukar 4 1,2,3,4 KBT College of EnggNashik, (India)

[6] An Online Examination System Using Wireless Security Application 1Madhu BabuAnumolu, 2N.Bharadwaj

[7] (2009) The Zigbee Alliance website [Online]. Available: http://www.zigbee.org/

[8] chae, M.J., Yoo, H.S., Kim, J.R., and cho, M.Y., "Bridge condition Monitoring System using Wireless Network".

[9] Prabhakar .S. Wang.J, Join, A.K., Pankanti.S, and Bolle, R.minutiae verification \& classification for finger print matching.

[10] Dr. Seetaiah Kilaru, Hari Kishore K, Sravani T, Anvesh Chowdary L, Balaji T "Review and Analysis of Promising Technologies with Respect to fifth Generation Networks", 2014 First International Conference on Networks \& Soft Computing, ISSN:978-1-47993486-7/14,pp.270-273,August2014.

[11] Meka Bharadwaj, Hari Kishore "Enhanced Launch-Off-Capture Testing Using BIST Designs" Journal of Engineering and Applied Sciences, ISSN No: 1816-949X, Vol No.12, Issue No.3, page: 636643, April 2017.
[12] P Bala Gopal, K Hari Kishore, B.Praveen Kittu "An FPGA Implementation of On Chip UART Testing with BIST Techniques", International Journal of Applied Engineering Research, ISSN 0973 4562, Volume 10, Number 14, pp. 34047-34051, August 2015

[13] A Murali, K Hari Kishore, D Venkat Reddy "Integrating FPGAs with Trigger Circuitry Core System Insertions for Observability in Debugging Process" Journal of Engineering and Applied Sciences, ISSN No: 1816-949X, Vol No.11, Issue No.12, page: 2643-2650, December 2016

[14] Mahesh Mudavath, K Hari Kishore, D Venkat Reddy "Design of CMOS RF Front-End of Low Noise Amplifier for LTE System Applications Integrating FPGAs" Asian Journal of Information Technology, ISSN No: 1682-3915, Vol No.15, Issue No.20, page: 40404047, December 2016

[15] N Bala Dastagiri, K Hari Kishore "Novel Design of Low Power Latch Comparator in $45 \mathrm{~nm}$ for Cardiac Signal Monitoring”, International Journal of Control Theory and Applications, ISSN No: 0974-5572, Vol No.9, Issue No.49, page: 117-123, May 2016.

[16] N Bala Gopal, Kakarla Hari Kishore "Reduction of Kickback Noise in Latched Comparators for Cardiac IMDs" Indian Journal of Science and Technology, ISSN No: 0974-6846, Vol No.9, Issue No.43, Page: 1-6, November 2016.

[17] S Nazeer Hussain, K Hari Kishore "Computational Optimization of Placement and Routing using Genetic Algorithm" Indian Journal of Science and Technology, ISSN No: 0974-6846, Vol No.9, Issue No.47, page: 1-4, December 2016.

[18] N.Prathima, K.Hari Kishore, "Design of a Low Power and High Performance Digital Multiplier Using a Novel 8T Adder", International Journal of Engineering Research and Applications, ISSN: 2248-9622, Vol. 3, Issue.1, Jan-Feb., 2013.

[19] T. Padmapriya and V. Saminadan, "Improving Throughput for Downlink Multi user MIMO-LTE Advanced Networks using SINR approximation and Hierarchical CSI feedback", International Journal of Mobile Design Network and Innovation- Inderscience Publisher, ISSN : 1744-2850 vol. 6, no.1, pp. 14-23, May 2015.

[20] S.V.Manikanthan and K.srividhya "An Android based secure access control using ARM and cloud computing", Published in: Electronics and Communication Systems (ICECS), 2015 2nd International Conference on 26-27 Feb. 2015, Publisher: IEEE, https://doi.org/10.1109/ECS.2015.7124833. 